\title{
Fluorescence induction of chlorophyll a in the Sargasso Sea and on the Grand Banks: correlation with photosynthetic capacity
}

\author{
Stephen S. Bates \& Trevor Platt \\ Marine Ecology Laboratory, Bedford Institute of Oceanography, Department of Fisheries and Oceans, Dartmouth, \\ Nova Scotia B2Y 4A2, Canada
}

\begin{abstract}
The induction of in vivo chlorophyll a fluorescence (increase in fluorescence intensity during a time-scale of ms) was tested as a measure of photosynthetic capacity of phytoplankton in the Sargasso Sea and at 2 stations, spatially and temporally distinct, on the Grand Banks of Newfoundland. The chlorophyll a-normalized area above the fluorescence induction curve, measured in the presence of the inhibitor DCMU $\left(\mathrm{A}_{\mathrm{DCMU}}[\mathrm{Chl} a]^{-1}\right)$, is assumed to be proportional to the pool-size of $\mathrm{Q}$, the primary electron acceptor of photosystem II. Positive correlations were found between $A_{\mathrm{DCMU}}\left(\mathrm{Chl}\right.$ a) ${ }^{-1}$ and the maximum rate of photosynthesis at light saturation at the 3 sampling locations. However, the slopes of the regressions differed among locations, suggesting that a unique relation is not possible for phytoplankton communities composed of different species and/or physiological states. Consideration of the tumover time of $Q$, in addition to its pool-size, may be necessary to interpret fluorescence induction completely in terms of photosynthetic capacity. Nevertheless, $A_{D C M U}(\mathrm{Chl} a)^{-1}$ provided a rapid way to obtain information about the depth distribution of relative photosynthetic activity, and about possible mechanisms of photoadaptation; values of $\mathrm{A}_{D C M U}(\mathrm{Chl} a)^{-1}$ generally increased during a 10 or $24 \mathrm{~h}$ incubation period at high irradiance levels, and decreased at low irradiance levels.
\end{abstract}

\section{INTRODUCTION}

Recently, we demonstrated the possibility of using the fluorescence induction (time-scale $\mathrm{ms}$ ) of in vivo chlorophyll $a(\mathrm{Chl}$ a) as a measure of photosynthetic capacity of phytoplankton (Bates \& Platt 1984). In that approach, which avoids the potentially deleterious effects of sample incubation, a dark-adapted sample is exposed to the actinic light of a specially designed induction fluorometer. The fluorescence intensity is then followed during several $\mathrm{ms}$ as it increases to a maximum $\left(F_{\max }\right)$ and as $Q$, the primary electron acceptor of photosystem II (PSII), becomes photoreduced in the presence of the herbicide 3-(3,4-dichlorophenyl)1,1-dimethylurea (DCMU); this is equivalent to a titration of $Q$ by photons (Malkin \& Kok 1966). The poolsize of $Q$ is proportional to the area above the fluorescence induction curve $\left(A_{D C M U}\right)$ when $D C M U$ is present (Malkin et al. 1981). Using laboratory cultures of Dunaliella tertiolecta and of Thalassiosira pseudonana, we found a significant positive correlation between $\mathrm{A}_{\mathrm{DCMU}}$ normalized to $\mathrm{Chl} a$ and $\mathrm{P}_{\mathrm{m}}^{\mathrm{B}}$, the $\mathrm{Chl}$

(c) Inter-Research/Printed in F. R. Germany a-normalized rate of photosynthesis at light saturation (Bates \& Platt 1984).

Here we extend the application of the fluorescence induction technique by using it to estimate the photosynthetic activity of natural populations of phytoplankton from the Sargasso Sea and from the Grand Banks of Newfoundland. We demonstrate a positive correlation between $\mathrm{A}_{\mathrm{DCMU}}(\mathrm{Chl} a)^{-1}$ and $\mathrm{P}_{\mathrm{m}}^{\mathrm{B}}$, but show that the relation differs among the sampling sites. We also show how fluorescence induction measurements provide a rapid way to assess the depth distribution of photosynthetic activity, and possible mechanisms of photoadaptation. Examples of fluorescence induction curves (time-scale s to min) from natural communities of phytoplankton are found in Vincent (1979), and Neveux \& Jupin (1981).

\section{MATERIALS AND METHODS}

Experiments were carried out in the Sargasso Sea and on the Scotian Shelf slope in April, 1983 (cruise 83- 
002; CSS 'Hudson') (Fig. 1a), and on the Grand Banks in July, 1984 (cruise 84-015; CGS Wilfred Templeman'), and in October, 1984 (cruise 84-028; CSS 'Dawson') (Fig. 1b). Water samples were collected at depths ranging from 1 to $70 \mathrm{~m}$ using either a submersible pumping system (Herman et al. 1984) in April and October, or Niskin bottles in July. Immediately after collection, $100 \mathrm{ml}$ triplicate samples were concentrated by deposition onto a GF/F glass fiber filter (24 mm diameter, Whatman Ltd.). During the Sargasso Sea cruise, 30 to $200 \mathrm{ml}$ of sample were filtered, and values of $F_{\max }$ and $A_{D C M U}$ were normalized to $100 \mathrm{ml}$. Three $\mathrm{ml}$ of DCMU $\left(10^{-5} \mathrm{M}\right.$ in filtered sea water

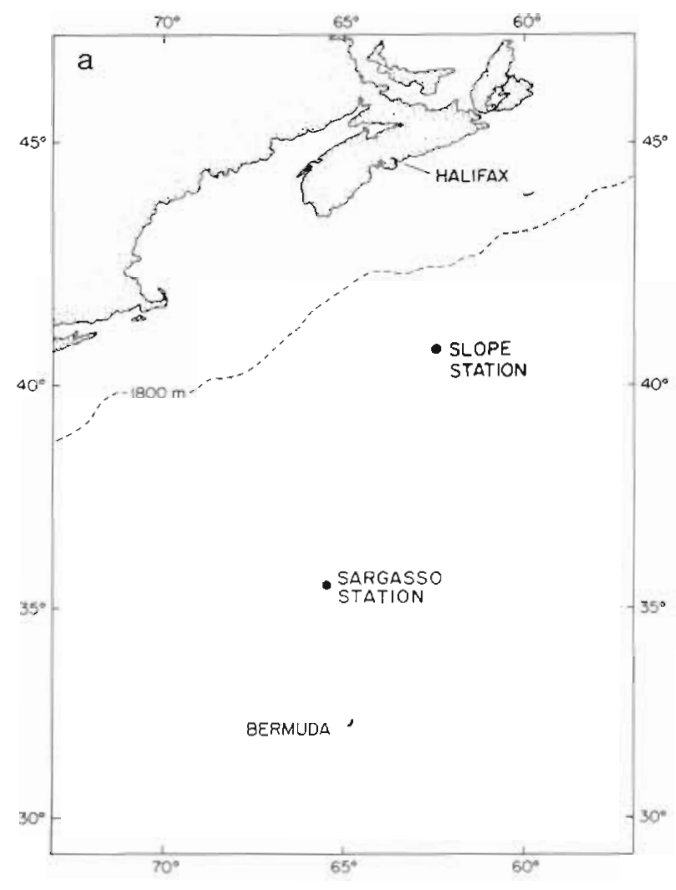

Fig. 1. Sampling Iocations in (a) the Sargasso Sea and on the Scotian Shelf slope in April (•), and (b) on the Grand Banks in July (•) and October ( $\mathbf{\square})$ obtained from a $10^{-3} \mathrm{M}$ ethanolic stock solution) were then added to the filter while only a thin layer of sea water remained above the cells deposited onto the filter. The DCMU remained in contact with the cells for either $10 \mathrm{~s}$ (Apr and Jul cruises) or $5 \mathrm{~min}$ (Oct cruise) before being suctioned through. Fluorescence measurements were then carried out either immediately (Jul and Oct cruises) or after about $4 \mathrm{~h}$ (Apr cruise), during which time the filters were placed in Petri dishes on ice and in darkness.

Fluorescence was measured in an induction fluorometer designed and built at the Bedford Institute of Oceanography (Bates \& Platt 1984). The actinic irradiance intensity at $458 \mathrm{~nm}$ was about $150 \mathrm{~W} \mathrm{~m}^{-2}$ in April, and about $20 \mathrm{~W} \mathrm{~m}^{-2}$ in July and October. The filter was held in place in the fluorometer with a specially-designed filter holder positioned at $45^{\circ}$ to the actinic light beam.

Care must be taken to properly 'condition' or 'adapt' the phytoplankton cells prior to obtaining a fluorescence induction curve. This insures that the thylakoid membranes within the chloroplast are 'deenergized' (intrathylakoid proton gradient dissipated) and that all of the electron traps are 'open' (Q oxidized) (Papageorgiou 1975), such that the fluorescence measurements reflect the entire photochemical capacity of the phytoplankton sample. We have recently investigated the effects of various preconditioning procedures using laboratory and field populations of phytoplankton (Bates 1985). Prior to this thorough investigation, samples from the Sargasso Sea were preconditioned in the fluorometer for $30 \mathrm{~s}$ in far-red $(720 \mathrm{~nm})$ light, followed by $1.5 \mathrm{~min}$ of darkness. During the Grand Banks cruises, samples were conditioned for $5 \mathrm{~min}$ in darkness in the fluorometer prior to measuring the fluorescence. 
The fluorescence induction signal was sent to a DL 912 transient recorder (Data Laboratories Ltd., Surrey, England) interfaced with an HP-85 microcomputer (Hewlett-Packard Co., Palo Alto, California). An HP-85 program integrated the area above the fluorescence induction curve $\left(A_{D C M U}\right)$ and determined the maximum fluorescence intensity $\left(F_{\max }\right)$ in the presence of DCMU. Geometrically, $A_{D C M U}$ is the area above the fluorescence induction curve bounded by a vertical axis situated at $0.2 \mathrm{~ms}$ after the initial rise in the fluorescence signal, and a horizontal line situated at $F_{\max } . A_{D C M U}$ is considered to be proportional to the concentration of $Q$, the primary electron acceptor of PSII (Bates \& Platt 1984).

Photosynthesis vs irradiance experiments were carried out on samples collected at the same locations and depths as used for the fluorescence induction measurements. In April (Sargasso Sea cruise), $100 \mathrm{ml}$ samples were incubated for $4 \mathrm{~h}$ with $25 \mu \mathrm{Ci}{ }^{14} \mathrm{C}$-bicarbonate (New England Nuclear Corp.) in a temperature-controlled linear light gradient box holding 40 light and 2 dark bottles (Irwin et al. 1983). In July and October (Grand Banks cruises), $1.0 \mathrm{ml}$ samples were incubated for $1 \mathrm{~h}$ with $15 \mu \mathrm{Ci}{ }^{14} \mathrm{C}$-bicarbonate in a modified photosynthetron (Lewis \& Smith 1983) made from an aluminum block providing 48 different light intensities. Incubations were terminated and samples were treated as previously described (Bates \& Platt 1984). The mathematical procedures used to extract $\mathrm{P}_{\mathrm{m}}^{\mathrm{B}}$ (Chl a-normalized photosynthetic rate at light saturation) from the photosynthesis-irradiance data are given in Platt et al. (1980).

Irradiance was measured with a $4 \pi$ collector (Biospherical Instruments Inc., San Diego, California). Chlorophyll a was detemined using a fluorometer (Model 10, Turner Designs), calibrated with pure Chl a (Sigma Chemical Co.). Depth profiles of in vivo Chl a fluorescence, temperature, and salinity were obtained with a CTD or a submersible pumping system (Herman et al, 1984).

\section{RESULTS}

\section{Sargasso Sea}

Temperature, salinity, nutrient and Chl a conditions in the Sargasso Sea (Fig. 2) were typical of those found by Menzel \& Ryther (1960). The surface layer was continuously well-mixed throughout the study period. A distinct Chl a maximum layer was absent; rather, the Chl a concentration increased slightly in the region of 30 to $70 \mathrm{~m}$ (Fig. 2c). A representative depth profile of $F_{\max }$ resembled that of $\mathrm{Chl}$ a concentration, except for an apparent maximum in $\mathrm{F}_{\max }$ at $50 \mathrm{~m}$ (Fig. $2 \mathrm{c}$ ). Depth profiles of $A_{D C M U}$ and of $A_{D C M U}(\mathrm{Chl} a)^{-1}$ were similar,

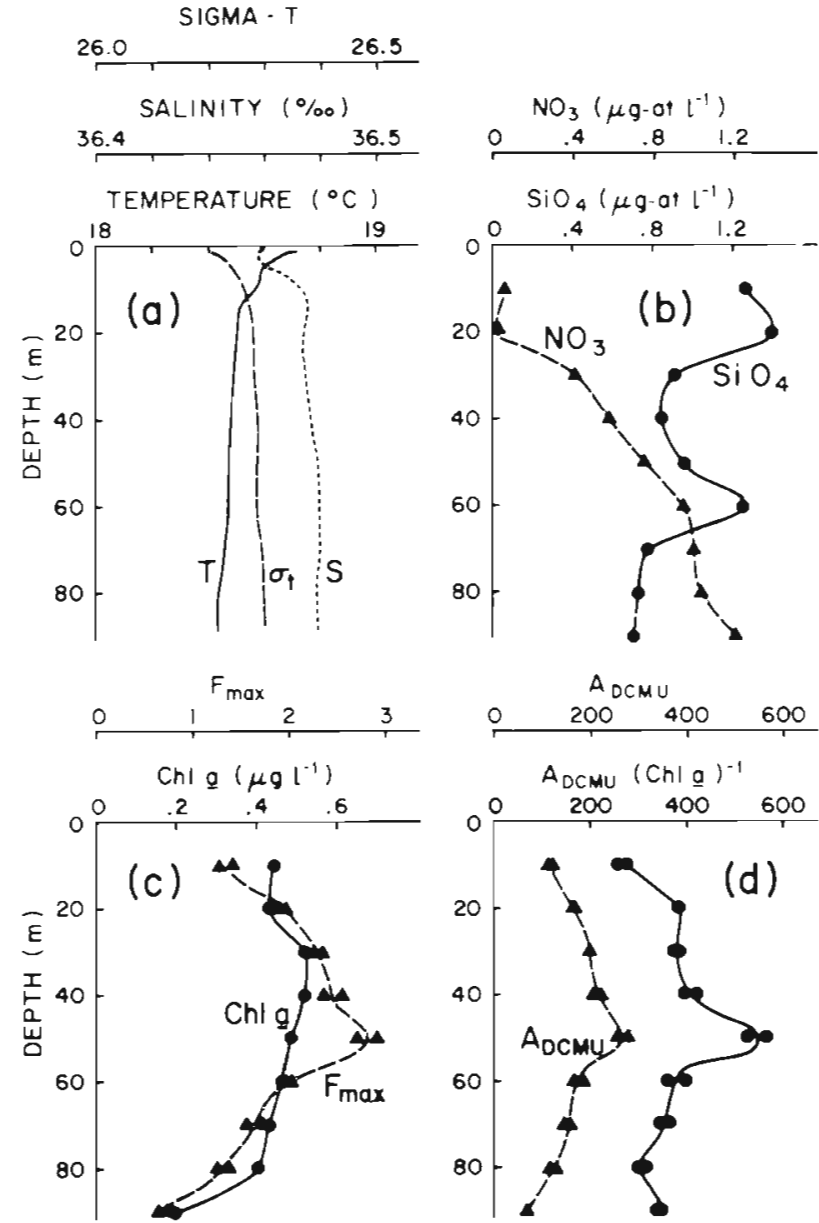

Fig. 2. Sargasso Sea station (April 17, 1983). Depth profiles of (a) temperature (-), salinity (---) and density structure $(---)$; (b) nitrate ( $\mathbf{\Delta})$ and silicate $(\bullet)$ concentration; (c) $F_{\max }(\boldsymbol{\Delta})$ and extracted Chl a ( concentration; (d) area above the fluorescence induction curve when normalized to sample volume (४) and to Chl $a(\bullet)$

and showed little structure (Fig. 2d), except for an apparent maximum at $50 \mathrm{~m}$ corresponding to the peak in $F_{\max }$.

Time courses for the change in biomass and fluorescence characteristics of a population incubated at 2 irradiance levels are shown in Fig. 3. A sample was collected at $80 \mathrm{~m}$ and incubated in a constant light chamber at high $\left(54.0 \mathrm{~W} \mathrm{~m}^{-2}\right)$ and at low $\left(0.1 \mathrm{~W} \mathrm{~m}^{-2}\right)$ irradiance levels (Fig. 3a, b). Another sample, collected at $30 \mathrm{~m}$, was incubated in a surface-water cooled deck box at $100 \%$ and $1 \%$ of the incident solar radiation (Fig. 3c, d). Chl a concentration decreased more under high than under low irradiance in both the constant light (Fig. 3a) and deck (Fig. 3c) incubations, but showed no evident periodicity. Values of $A_{D C M U}$ $(\mathrm{Chl} \mathrm{a})^{-1}$ were likewise relatively constant in the deck box at both high and low irradiance levels for about the first $8 \mathrm{~h}$ of incubation (Fig. 3d). After sunset, however 

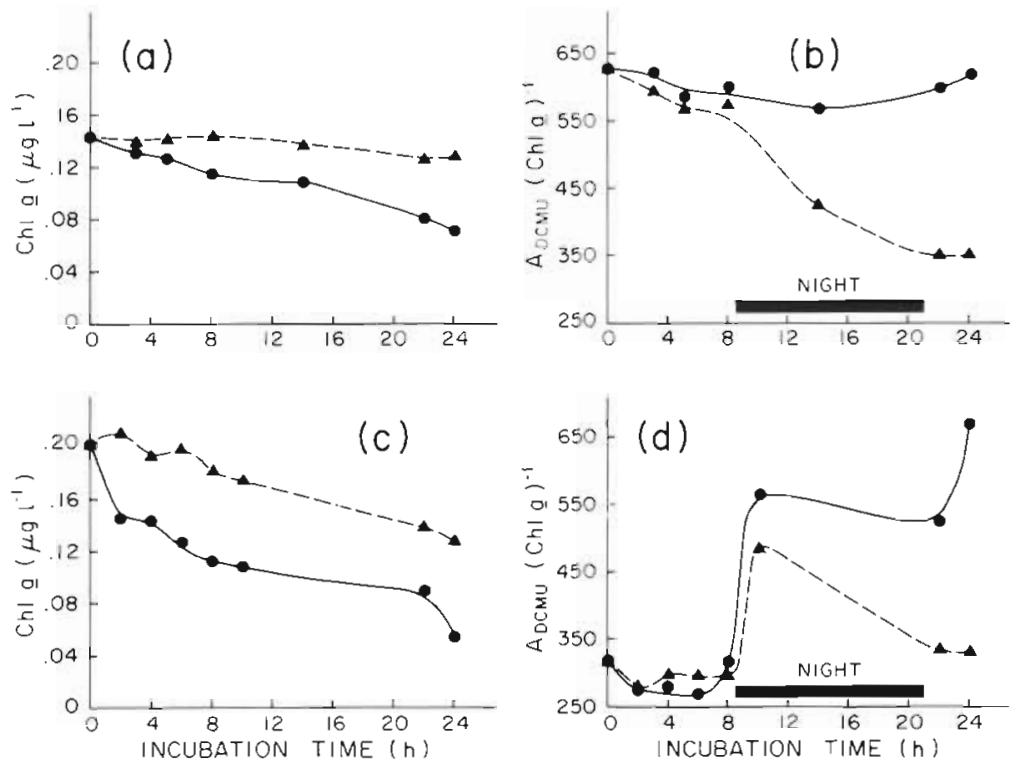

Fig. 3. Sargasso Sea station. Time course of change in $(a, c)$ Chl a concentration and $(b, d)$ $\mathrm{Chl}$ a-normalized area above the fluorescence induction curve (ADCMU $[\mathrm{Chl} a]^{-1}$ ) at high $(\bullet)$ and low $(\boldsymbol{\Lambda})$ irradiance level; $(a, b)$ sample collected at $80 \mathrm{~m}$ (April 17) and incubated in a constant light chamber at $54.0 \mathrm{~W} \mathrm{~m}^{-2}(\bullet)$ and $0.1 \mathrm{~W} \mathrm{~m}^{-2}(\mathbf{\Lambda})$ of irradiance; (c, d) sample collected at $30 \mathrm{~m}$ (April 13) and incubated in deck boxes at $100 \%(\bullet)$ and $1 \%(\mathbf{4})$ of incident solar radiation

$\mathrm{A}_{\mathrm{DCMU}}(\mathrm{Chl} a)^{-1}$ increased in both the $100 \%$ and $1 \%$ irradiance samples; after sunrise, ADCMU $(\mathrm{Chl} \mathrm{a})^{-1}$ further increased in the $100 \%$ irradiance sample, but decreased in the $1 \%$ irradiance sample.

\section{Grand Banks: July}

On the Grand Banks in July, the surface layer was mixed down to about $15 \mathrm{~m}$ (Fig. 4a). Nitrate and phosphate concentrations were generally low in the surface layer extending down to about $30 \mathrm{~m}$ (Fig. 4b). A representative depth profile of $F_{\max }$ showed a peak at $30 \mathrm{~m}$; Chl a concentration showed a maximum at $40 \mathrm{~m}$ (Fig. 4c). The region of highest biomass corresponded roughly to a second, deeper pycnocline (Fig. 4a) and the layer of lowest nutrient concentration (Fig. 4b). A maximum in $A_{D C M U}(\mathrm{Chl} \mathrm{a})^{-1}$ occurred at about $20 \mathrm{~m}$ (Fig. 4d), just below the shallow pycnocline.

Examples of photosynthesis vs irradiance curves used to obtain $\mathrm{P}_{\mathrm{m}}^{\mathrm{B}}$ in July are given in Fig. 5. Samples taken from within the mixed layer showed little or no photoinhibition (Fig. 5a, b); photounhibition was evident in samples collected from below the mixed layer (Fig. 5c, d). Similar observations have been reported, for example, by Platt et al. (1982) in Baffin Bay for phytoplankton populations taken from above and below the pycnocline, respectively.

\section{Grand Banks: October}

The physical oceanographic situation observed on the Grand Banks in October (Fig. 6a) was similar to that seen in July; the mixed layer extended down only
SIGMA - T

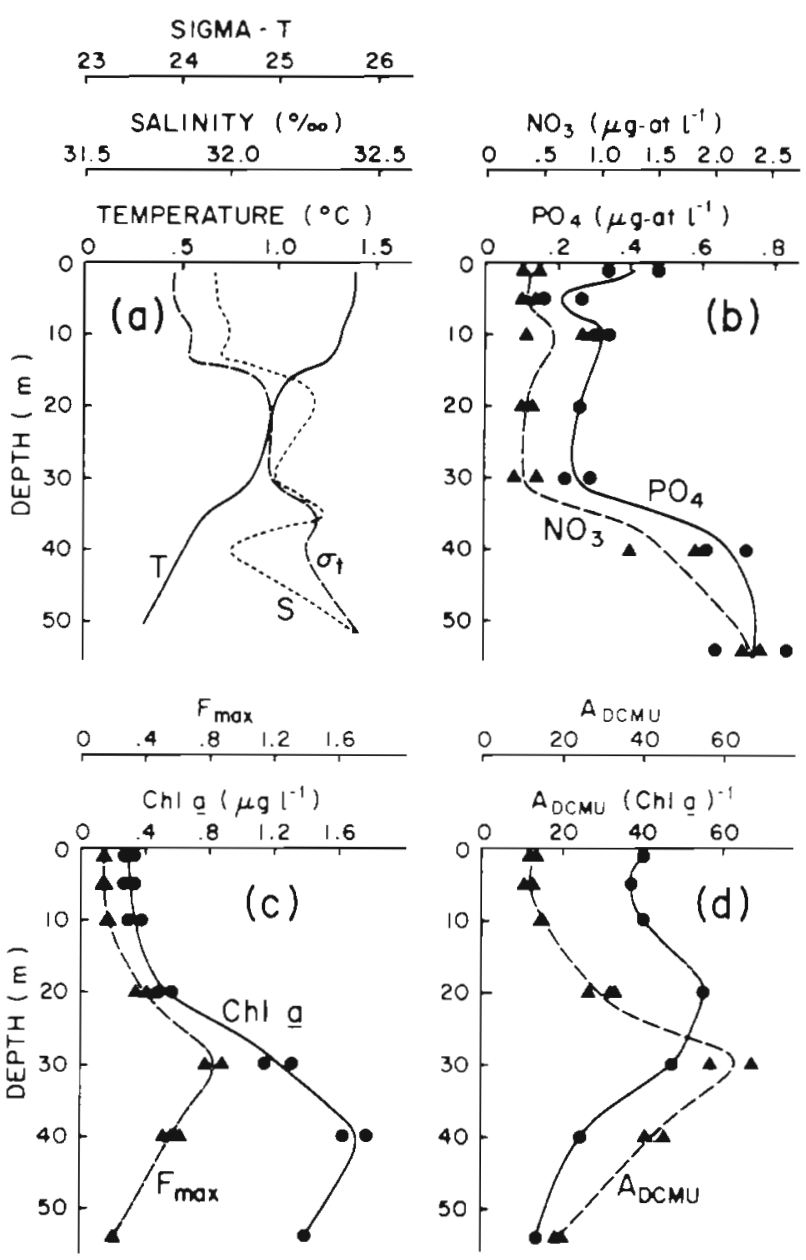

Fig. 4. Grand Banks Station 34 (July 15, 1984). Depth profiles of (a) temperature (-), salinity $(---)$ and density structure $(--)$; (b) nitrate $(\mathbf{\Delta})$ and phosphate $(\bullet)$ concentration; (c) $F_{\max }$ $(\Delta)$ and extracted Chl a concentration ( $\bullet$ ); (d) area above the fluorescence induction curve when normalized to sample

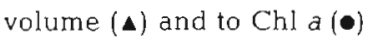



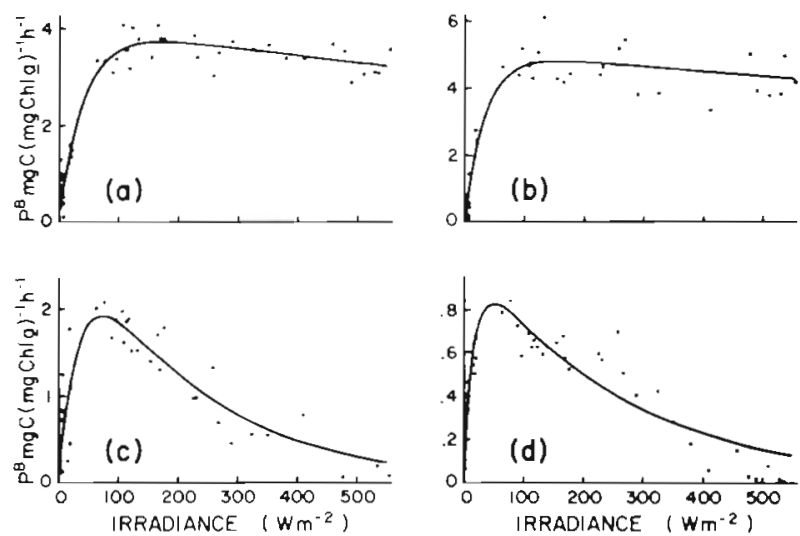

Fig. 5. Grand Banks, July. Representative photosynthesis vs irradiance curves at (a) Station 45 (6 m); (b) Station 51 (5 m); (c) Station $16(30 \mathrm{~m})$; (d) Station $24(20 \mathrm{~m})$

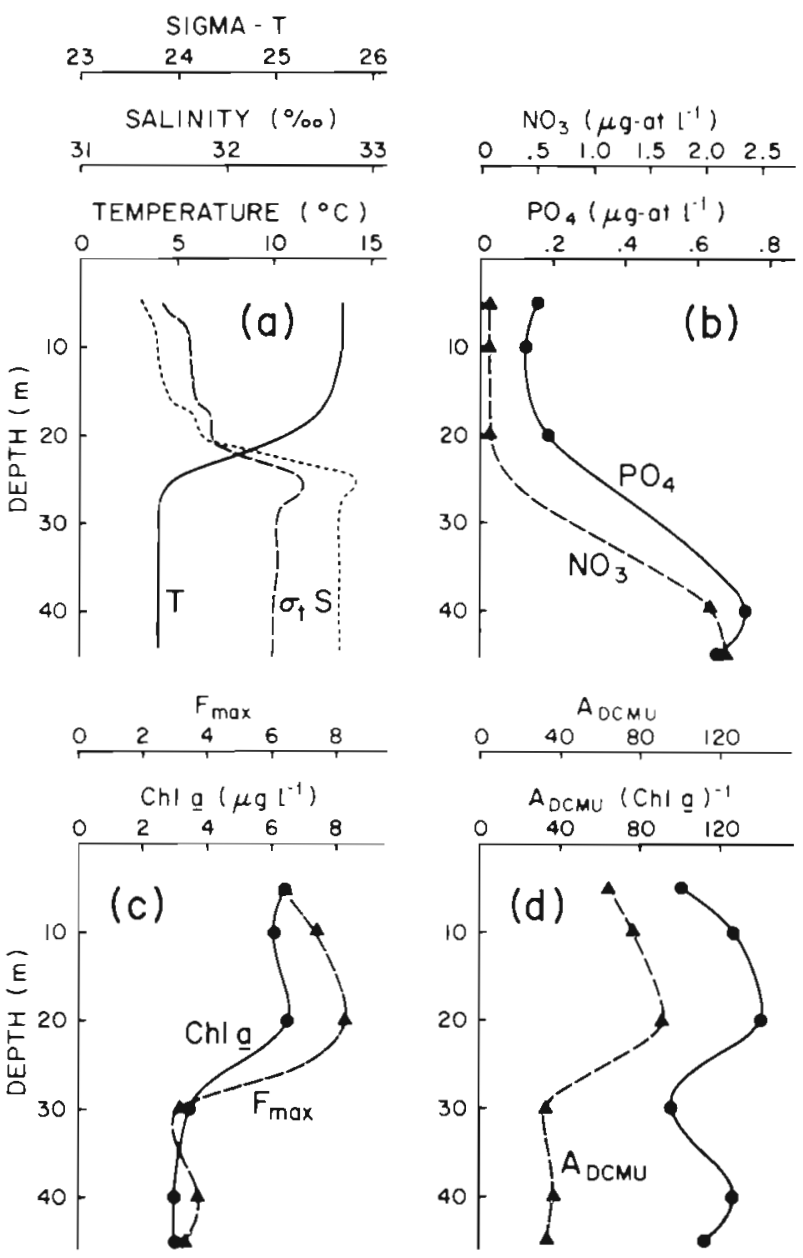

Fig. 6. Grand Banks (October 10, 1984). Depth profiles; see Fig 4 for symbols and explanation

slightly deeper to $20 \mathrm{~m}$. Biomass, in terms of Chl $a$ and $F_{\max }$, was relatively evenly distributed throughout the mixed layer, and decreased below the pycnocline (Fig. $6 c)$. The depth distribution of $A_{D C M U}(\mathrm{Chl} \mathrm{a})^{-1}$ and
$A_{\text {DCMU }}$ (Fig. 6d) was similar to that of Chl a and $F_{\text {max }}$.

A time-course experiment, similar in principle to that carried out in the Sargasso Sea, was performed on the Grand Banks in October. Samples were collected within $(5 \mathrm{~m})$ and below ( $45 \mathrm{~m}$ ) the mixed layer, and were incubated in deck boxes at $100 \%$ and $10 \%$ of the incident solar radiation. As in the Sargasso Sea experiment (Fig. 3), little change was seen in the Chl a concentration for samples incubated at $10 \%$ of the incident light (Fig. $7 \mathrm{a}, \mathrm{c}$ ). Samples incubated at full irradiance began to show a decrease in Chl a concentration after 4 to $5 \mathrm{~h}$ (Fig. $7 \mathrm{a}, \mathrm{c}$ ). The depth at which the samples were collected did not significantly influence the magnitude of the decrease in Chl a concentration.

In contrast to the similarity in the pattern of change in Chl a concentration over time for the 5 and $45 \mathrm{~m}$ samples (Fig. $7 \mathrm{a}, \mathrm{c}$ ), the time course of change in $A_{\text {DCMU }}$ $(\mathrm{Chl} a)^{-1}$ differed for these samples (Fig. 7b, d). After about $6 \mathrm{~h}$ of incubation, the $5 \mathrm{~m}$ sample showed an increase in $\mathrm{A}_{D C M U}(\mathrm{Chl} \mathrm{a})^{-1}$ at full sunlight, and a decrease at the $10 \%$ irradiance level (Fig. $7 \mathrm{~b}$ ). The $45 \mathrm{~m}$ sample, on the other hand, exhibited a more immediate and pronounced decline in $A_{D C M U}(\mathrm{Chl} a)^{-1}$ at the $10 \%$ irradiance level (Fig. $7 \mathrm{~d}$ ). The pattern seen for the aliquot incubated at full sunlight (Fig. $7 \mathrm{~d}$ ) is more difficult to interpret. Disregarding the low value at $3.4 \mathrm{~h}, \mathrm{~A}_{D C M U}(\mathrm{Chl} \mathrm{a})^{-1}$ remained high toward the end of the incubation, as was observed for the other $100 \%$ irradiance incubations reported above (Fig. 3b, d; Fig. 7b).

\section{Relations between fluorescence and other biological parameters}

Relations between fluorescence parameters, Chl a biomass, and photosynthetic rates are shown in Fig. 8. Strong positive correlations were found between in vivo $\mathrm{F}_{\max }$ and extracted $\mathrm{Chl}$ a for the Sargasso Sea (Fig. 8a) and Grand Banks (Fig. 8b) samples. However, the slopes for the regressions differed significantly among the study areas; Sargasso Sea data gave values of $F_{\max }$ about 10 times greater than the Grand Banks values, and $F_{\max }$ values for the Grand Banks in October were about twice as great as those in July. The regression showed least residual variance for the October Grand Banks data which represent only 1 station during a $2 \mathrm{~d}$ period, compared to several stations during 2 wk for the July Grand Banks and Sargasso Sea stations.

The differences found in $\mathrm{F}_{\max }$ were also reflected in differences in $A_{D C M U}$ and $A_{D C M U}(\mathrm{Chl} a)^{-1}$ among the study areas. Nevertheless, positive relations were found between $A_{D C M U}$ and $P_{m}$ (Fig. 8c, d), and between $A_{\text {DCMU }}(\mathrm{Chl} a)^{-1}$ and $P_{m}^{B}$ (Fig. 8e, f). 

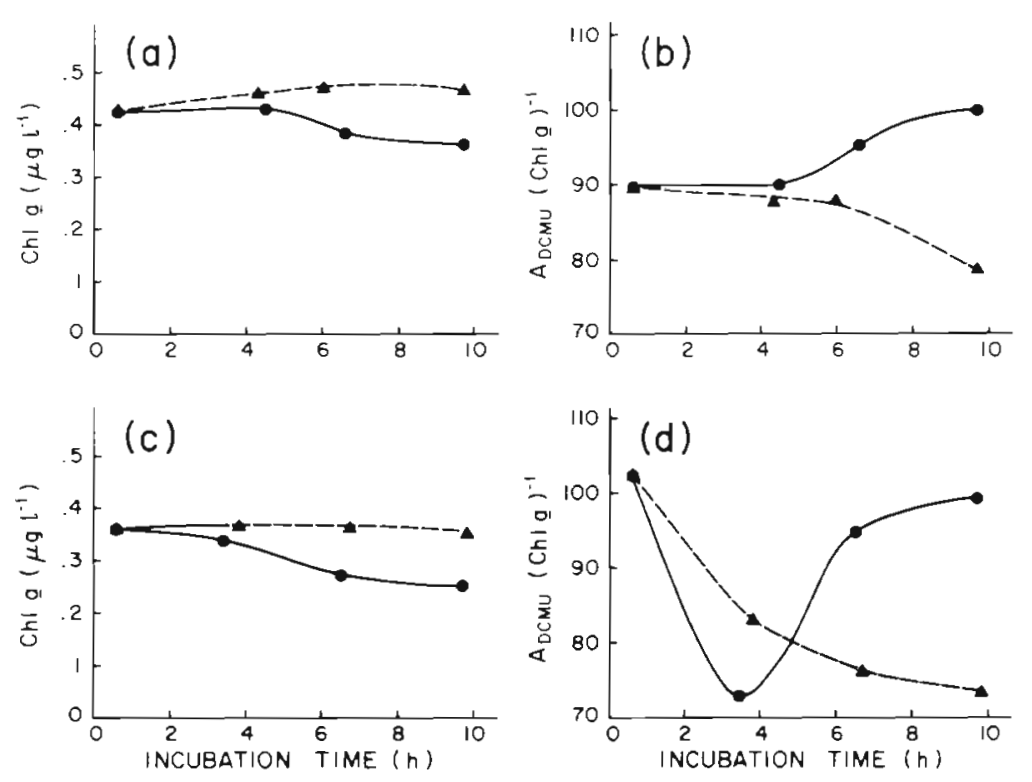

Fig. 7. Grand Banks (October 9, 1984). Time course of change in $(a, c)$ Chl a concentration and (b, d) Chl $a$-normalized area above the fluorescence induction curve $\left(\mathrm{A}_{\mathrm{DCMU}}[\mathrm{Chl} a]^{-1}\right)$ at $100 \%(\bullet)$ and $10 \%(\Delta)$ of the incident solar radiation in deck boxes. Samples were collected at $5 \mathrm{~m}(\mathrm{a}, \mathrm{b})$ and at $45 \mathrm{~m}(\mathrm{c}, \mathrm{d})$
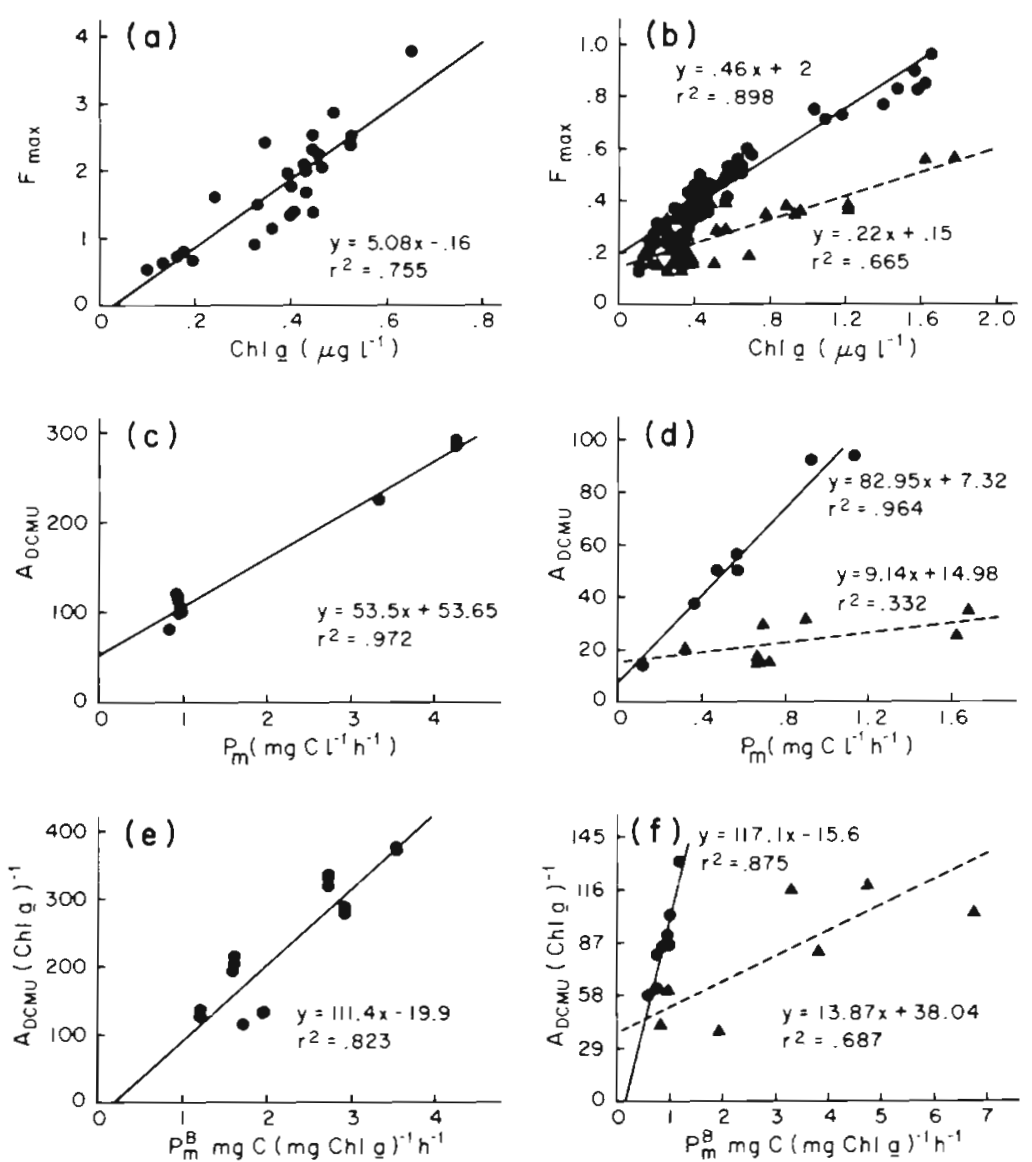

Fig. 8. Relation between ( $a, b)$ maximum fluorescence intensity in the presence of DCMU $\left(\mathrm{F}_{\max }\right)$ and extracted $\mathrm{Chl}$ a concentration; (c, d) photosynthetic rate at light saturation $\left(\mathrm{P}_{\mathrm{m}}\right)$ and the area above the fluorescence induction curve $\left(A_{D C M U}\right) ;$ and $(e, f)$ Chl a-normalized photosynthetic rate at light saturation $\left(\mathrm{P}_{\mathrm{m}}^{B}\right)$ and $\mathrm{Chl} \mathrm{a}^{-}$ normalized area above the fluorescence induction curve $\left(A_{D C M U}[C h l ~ a]^{-1}\right)$. Samples were collected at the Sargasso Sea and Slope stations $(a, c, e)$, and on the Grand Banks $(b, d, f)$ in July (4) and October (•)

\section{EVALUATION AND DISCUSSION}

Two ecologically and physically distinct environments were sampled to test, to our knowledge for the first time, the use of in vivo Chl a fluorescence induction as a measure of photosynthetic activity in the field. The Sargasso Sea (Fig. 2) was characterized by a low phytoplankton biornass of low quantum yield (Lewis et 
al. 1985), suspended in a well-mixed water column. Active cyanobacteria were present (Li \& Dickie 1985), and the $<1 \mu \mathrm{m}$ size fraction accounted for 25 to $30 \%$ of the total production (B. Irwin unpubl.). The Grand Banks had slightly more Chl a, especially in October, and the mixed layer extended down to only 15 to $25 \mathrm{~m}$ (Fig. 4 \& 6). The dynamics of the Grand Banks microplankton during the July and October cruises is discussed by R. E. H. Smith (unpubl.).

In both environments, the biomass was too low, using the present fluorometer, to measure adequately the fluorescence induction of natural concentrations of in vivo $\mathrm{Chl}$ a suspended in a water sample. Phytoplankton therefore had to first be concentrated onto a glass fiber filter before the fluorescence induction signal could be measured. This could potentially introduce artifacts, some of which were discussed previously (Bates 1985). Briefly, laboratory studies showed a faster rise time of the fluorescence signal and a larger $\mathrm{F}_{\max }$ when the fluorescence was measured from a culture sample deposited onto a glass fiber filter compared to a signal obtained directly from a liquid sample in a cuvette. This could be due to an intensification of the photon flux because of multiple scattering within the filter, and could lead to more absorption of light on the filter compared to the liquid sample (cf. Mitchell \& Kiefer 1984). Neveux \& Jupin (1981) believed that deposition of algae onto glass fiber filters perturbed their photosynthetic ability. Optical problems could also be created when Chl $a$ on the filter exceeds $2.5 \mu \mathrm{g} \mathrm{cm}^{-2}$ (Neori et al. 1984). In our study, no more than $0.4 \mu \mathrm{g} \mathrm{Chl} \mathrm{a} \mathrm{cm}^{-2}$ was filtered, and the value was usually less than $0.04 \mu \mathrm{g} \mathrm{Chl} \mathrm{a} \mathrm{cm}^{-2}$. In spite of these potential problems, glass fiber filters are used with success to concentrate field samples prior to measuring fluorescence and absorption spectra (Yentsch \& Yentsch 1979, Kiefer \& SooHoo 1982, Mitchell \& Kiefer 1984, Neori et al. 1984, Lewis et al. 1985).

\section{Fluorescence induction as a measure of photosynthe- tic capacity}

The usefulness of the fluorescence induction technique to biological oceanographers would lie in its ability to estimate photosynthetic capacity (photosynthetic rate at light saturation). However, the difficulty is in finding a standard against which the fluorescence induction method can be compared. Discrepancies in photosynthetic rates may be evident when measured by ${ }^{14} \mathrm{C}$ uptake, $\mathrm{O}_{2}$ evolution or by infra-red gas analysis (Peterson 1980, Richardson et al. 1983, Holligan et al. 1984, Smith et al. 1984). It may therefore not be ideal to compare results of the fluorescence induction techni- que with, say, the ${ }^{14} \mathrm{C}$-technique, which is itself under criticism as a method for measuring primary production. Nevertheless, laboratory studies using phytoplankton cultures have shown strong positive correlations between $A_{D C M U}(\mathrm{Chl} a)^{-1}$ and $\mathrm{P}_{\mathrm{m}}^{\mathrm{B}}$ measured by ${ }^{14} \mathrm{C}$ uptake in a situation where many of the criticisms against the ${ }^{14} \mathrm{C}$-technique are not valid (Bates \& Platt 1984). With this in mind, and with no alternatives at present, fluorescence induction will be compared with the conventional ${ }^{14} \mathrm{C}$-technique for measuring photosynthetic capacity.

The high positive correlations found between $A_{D C M U}$ and $P_{m}$ (Fig. $8 \mathrm{C}, d$ ) and between $A_{D C M U}(C h l a)^{-1}$ and $P_{m}^{B}$ (Fig. $8 \mathrm{e}, \mathrm{f}$ ) are encouraging. The relation was better when expressed on a water volume rather than on a Chl $a$ basis in the Sargasso Sea and on the Grand Banks in October. However, both the magnitude of the $A_{D C M U}$ values and the slopes of the regressions are different in the Sargasso Sea and on the Grand Banks in July and in October. These differences could be real or artificial. It is known, for example, that a given value of $A_{D C M U}$ is a function of the physiological state of the phytoplankton (of interest here), of the procedure used to 'precondition' the cells prior to measuring the fluorescence induction curve, and finally of the irradiance intensity used to excite the Chl a fluorescence (Bates 1985).

In the Sargasso Sea, samples were preconditioned in the fluorometer for $30 \mathrm{~s}$ in far-red $(720 \mathrm{~nm})$ light, followed by $1.5 \mathrm{~min}$ of darkness; the actinic irradiance was also high (about $150 \mathrm{~W} \mathrm{~m}^{-2}$ at $458 \mathrm{~nm}$ ). The combination of these factors was previously shown to result in large values of $F_{\max }$ and of $A_{D C M}$ relative to dark adaptation for $5 \mathrm{~min}$ and use of a lower (20 to $30 \mathrm{~W}$ $\mathrm{m}^{-2}$ ) actinic irradiance level (Bates 1985). The latter preconditioning was used during the Grand Banks cruises. This undoubtedly contributes to the significantly larger values of $A_{D C M U}$ observed in the Sargasso Sea (Fig. 8c) compared to the Grand Banks (Fig. 8d). On the other hand, the same actinic irradiance level (about $20 \mathrm{~W} \mathrm{~m}^{-2}$ ) and dark adaptation time $(5 \mathrm{~min}$ ) were used in July as in October on the Grand Banks, yet the slopes for the regression between $A_{D C M U}$ and $P_{m}$ were different, and values of $A_{D C M U}$ were larger in October than in July (Fig. 8d). It may therefore be concluded that the differences in fluorescence properties observed between the July and October cruises are not artifacts, but are due to physiological and/or species differences between the phytoplankton communities sampled at 2 distinct times of the year and locations on the Grand Banks. Photosynthesis was mainly in the $<5 \mu \mathrm{m}$ size fraction at both times, but in October, large dinoflagellates were present and contributed 20 to $40 \%$ to the total photosynthesis. Flagellates, including small Gyrodinium and Gymnodinium 
spp. were present in the $<5 \mu \mathrm{m}$ fraction in both July and October (R. E. H. Smith pers. comm.).

As an indication that 2 physiologically different populations were present, we observed distinct slopes for the relation between $F_{\max }$ and extracted Chl a (Fig. 8b), where $F_{\max }$ is the maximum in vivo Chl a fluorescence intensity in the presence of DCMU. In this sense, the measurement is analogous to that made by Slovacek \& Hannan (1977), who found a constant relation between extracted $\mathrm{Chl} a$ and fluorescence intensity, measured in the presence of DCMU, for phytoplankton of diverse physiological states. However, in contrast to their results, the fluorescence yields in the 2 communities in July and October were not constant. This may also occasionally be seen in a given depth profile where values of $F_{\max }$ and of $\mathrm{Chl}$ a do not always coincide at all depths (Fig. 2c, 4c). Roy \& Legendre (1979) and Prézelin \& Ley (1980) also reported a nonconstant relation between in vivo fluorescence intensity in the presence of DCMU and extracted Chl $a$.

The Chl a-normalized area above the fluorescence induction curve $\left(\mathrm{A}_{\mathrm{DCMU}}[\mathrm{Chl} a]^{-1}\right)$ is interpreted to be proportional to the number of PSI photosynthetic units (PSU) (Malkin et al. 1981). The range in values of $A_{D C M U}(C h l a)^{-1}$ found in July overlapped that found in October (Fig. 8f). This suggests that the number of PSU was similar in the populations studied in July and in October. In spite of this implied similarity in PSU number, the range in observed $\mathrm{P}_{\mathrm{m}}^{\mathrm{B}}$ (Fig. 8f) was more

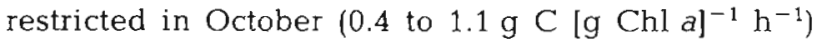
than in July $\left(0.8\right.$ to $\left.6.7 \mathrm{~g} \mathrm{C}[\mathrm{g} \mathrm{Chl} a]^{-1} \mathrm{~h}^{-1}\right)$. Thus, for the same value of $\mathrm{A}_{\mathrm{DCMU}}(\mathrm{Chl} \mathrm{a})^{-1}$, one observed a greater $\mathrm{P}_{\mathrm{m}}^{\mathrm{B}}$ in July than in October, perhaps to be explained by a faster turnover of $Q$ (the primary electron acceptor in PSII) in July than in October (cf. Falkowski et al. 1984). This demonstrates the importance, in future work, of measuring not just the poolsize of $Q$, but also its turnover rate.

\section{Depth profiles of fluorescence parameters}

In spite of the different relations between $A_{D C M U}$ $(\mathrm{Chl} \mathrm{a})^{-1}$ and $\mathrm{P}_{\mathrm{m}}^{\mathrm{B}}$ for the 3 areas studied, one may still interpret depth profiles and time courses for the change in $A_{D C M U}$ for a given location. Depth profiles generally showed a maximum in $A_{D C M U}$ and in $A_{D C M U}$ $(\mathrm{Chl} a)^{-1}$ associated with a peak in $\mathrm{F}_{\max }$ and at a depth just above where nitrate begins to increase (Fig. 2, 4 \& $6)$. This feature was seen in the Sargasso Sea even though the water column was well-mixed (Fig. 2); on the Grand Banks, the peak in $A_{D C M U}(\mathrm{Chl} a)^{-1}$ was generally located within or just below the pycnocline (Fig. $4 \& 6$ ). These would presumably be the depths at which $\mathrm{P}_{\mathrm{m}}^{\mathrm{B}}$ would also be maximum. In this way, fluorescence induction measurements provide a rapid means to assess the depth distribution of photosynthetic activity.

\section{Time course of photoadaptation}

Results of the light shift experiments (Fig. 3 \& 7) indicate that $A_{D C M U}(C h l a)^{-1}$ is a dynamic property which may provide information about mechanisms of photoadaptation. Incubating a phytoplankton community at a high irradiance level generally resulted in a decrease in Chl a concentration and an increase in $\mathrm{A}_{\mathrm{DCMU}}(\mathrm{Chl} \mathrm{a})^{-1}$ (Fig. 3 \& 7 ). Incubation at a low irradiance level did not significantly change Chl a concentration, but $A_{D C M U}$ (Chl a) ${ }^{-1}$ decreased (Fig. 3 \& 7). The decrease in $\mathrm{A}_{\mathrm{DCMU}}\left(\mathrm{Chl}\right.$ a) ${ }^{-1}$ at low irradiance levels could be interpreted in 2 ways: (1) it could reflect an actual decrease in $\mathrm{P}_{\mathrm{m}}^{\mathrm{B}}$ as the correlation between $A_{D C M U}(C h l a)^{-1}$ and $P_{m}^{B}$ suggests (Fig. 8e, f). For the Grand Banks data (Fig. 7d), this is supported by the finding of a lower $\mathrm{P}_{\mathrm{m}}^{\mathrm{B}}$ at the end of the incubation $\left(0.6 \mathrm{~g} \mathrm{C}\left[\mathrm{g} \mathrm{Chl} \mathrm{a}^{-1} \mathrm{~h}^{-1}\right)\right.$ than at the beginning $(1.0 \mathrm{~g} \mathrm{C}$ [g Chl a $]^{-1} \mathrm{~h}^{-1}$ ). In this case, longer than 10 or $24 \mathrm{~h}$ would be required for the cells to 'adapt' to the low irradiance condition. (2) Alternatively, the decrease in $A_{D C M U}(\mathrm{Chl} \mathrm{a})^{-1}$ suggests that, although the number of PSU is decreasing, the size of the photon-capturing PSU antenna (i.e. Chl a $\left[\mathrm{A}_{\mathrm{DCMU}}\right]^{-1}$ ) is actually increasing. Falkowski (1983) found that a natural phytoplankton community, dominated by Coscinodiscus spp., became shade adapted by increasing its PSU size, as measured by an increase in $\mathrm{Chl} / \mathrm{P}_{700}$ ratio, where $\mathrm{P}_{700}$ is the reaction center of photosystem $\mathrm{I}$. Whether the populations photoadapt by changing the number or size of PSU, the turnover time of $Q$ should also be considered. For example, a decrease in the number of PSU could be offset by a shorter turnover time of the $Q$ pool.

The presence of a photoperiod could complicate the interpretation of a photoadaptation experiment. Post et al. (1984) found a circadian periodicity in Chl a cell-1 that was distinct from effects due to a light shift for a culture of Thalassiosira weissflogii. However, Chl a/ $\mathrm{P}_{700}$ ratios, reflecting PSU size, of a natural bloom of Coscinodiscus spp. did not vary diurnally (Falkowski 1983). Prézelin \& Ley (1980) observed a strong diurnal periodicity in in vivo fluorescence of Chl a in the presence of DCMU, that was independent of Chl a concentration. During a light shift experiment under natural light in the Sargasso Sea, samples incubated under both high and low irradiance levels showed a large increase in $\mathrm{A}_{\mathrm{DCM}}(\mathrm{Chl} a)^{-1}$ several hours after sunset (Fig. 3d). The concentration of Chl a did not parallel this change (Fig. $3 \mathrm{c}$ ). Nor was there an abrupt 
increase in $\mathrm{A}_{\mathrm{DCMU}}(\mathrm{Chl} \mathrm{a})^{-1}$ when a sample from the same station $3 \mathrm{~d}$ later was incubated in a constant light chamber (Fig. 3b). The mechanisms for such an abrupt change in $\mathrm{A}_{\mathrm{DCMU}}\left(\mathrm{Chl}\right.$ a) ${ }^{-1}$ under natural light are not clear, but the finding suggests that cells may not always distinguish diurnal changes in irradiance from those associated with vertical movement of the cells within the euphotic zone.

\section{Future improvements of the technique}

These first measurements of fluorescence induction properties at sea are promising, but point out several changes that should be made to improve the technique for use in field situations:

(1) The sensitivity of the fluorometer must be increased to allow the fluorescence of a liquid sample to be measured. This would eliminate potential artifacts due to concentrating the sample onto a glass fiber filter. A photomultiplier tube has replaced the less-sensitive photodiode in our recently-modified induction fluorometer.

(2) The relation between $A_{D C M U}\left(\mathrm{Chl}_{a}\right)^{-1}$ and $\mathrm{P}_{\mathrm{m}}^{\mathrm{B}}$ although positive and linear, was not a constant for the 3 environments studied. This was due in part to changes from cruise to cruise in the actinic irradiance level and in the preconditioning procedure used as the technique was being developed. However, $F_{\max }$ and $A_{D C M U}$ from the Grand Banks, where the methodology was more uniform, suggests that physiological differences in the phytoplankton communities may also be responsible. Information on the turnover time of $\mathrm{Q}$ may be required to estimate photosynthetic capacity directly, without the need to rely on calibration curves as is presently the case. Turnover times of $Q$ would also help to interpret changes in $A_{D C M U}$ observed in photoadaptation experiments.

(3) The induction fluorometer used in this study was designed to excite and detect only the fluorescence emitted directly from Chl a. It is currently not known how the presence of varying proportions of phycobilincontaining cyanobacteria of varying physiological states (such as were found in the Sargasso Sea) would alter the relation between $\mathrm{A}_{\mathrm{DCMU}}(\mathrm{Chl} \text { a) })^{-1}$ and $\mathrm{P}_{\mathrm{m}}^{\mathrm{B}}$. Our recently-modified induction fluorometer allows the choice of different excitation and emission wavelengths to measure the fluorescence originating from phycocyanin and phycoerythrin as well as from Chl a.

Acknowledgements. We thank B. Irwin for supervising the photosynthesis-irradiance experiments in the Sargasso Sea, M. Paranjape for some of the Chl a data from the October Grand Banks cruise, E. Larsen for continued electronic development of the fluorometer, and W. Richard and E. Horne for help with the inter-computer transfer of data. R. E. H. Smith kindly commented on the manuscript. SSB was supported in part by funds from the Office of Energy Research and Development (OERD)

\section{LITERATURE CITED}

Bates, S. S. (1985). Sample preconditioning for measurement of fluorescence induction of chlorophyll $a$ in marine phytoplankton. J. Plankton Res. 7: in press

Bates, S. S., Platt, T (1984). Fluorescence induction as a measure of photosynthetic capacity in marine phytoplankton: response of Thalassiosira pseudonana (Bacillariophyceae) and Dunaliella tertiolecta (Chlorophyceae). Mar. Ecol. Prog. Ser. 18: 67-77

Falkowski, P. G. (1983). Light-shade adaptation and vertical mixing of marine phytoplankton: A comparative field study. J. mar. Res. 41: 215-237

Falkowski, P. G., Wyman, K., Mauzerall, D. (1984). Effects of continuous background irradiance on xenon-flashinduced fluorescence yields in marine microalgae. In: C. Sybesma (ed.) Advances in photosynthesis research. Vol. 1. Dr. W. Junk, The Hague p. 163-166

Herman, A. W., Mitchell, M. R., Young, S. W. (1984). A continuous pump sampler for profiling copepods and chlorophyll in the upper oceanic layers. Deep Sea Res. 31: 439-450

Holligan, P. M., Williams, P. J. leB., Purdie, D., Harris, R. P. (1984). Photosynthesis, respiration and nitrogen supply of plankton populations in stratified, frontal and tidally mixed shelf waters. Mar. Ecol. Prog. Ser. 17: 201-213

Irwin, B., Harris, L., Dickie, P., Lindley, P., Platt, T. (1983). Phytoplankton productivity in the eastern Canadian Arctic during July and August 1980. Can. Data Report Fish. Aquat. Sci. No. 386,157 p.

Kiefer, D. A., SooHoo, J. B. (1982). Spectral absorption by marine particles of coastal waters of Baja California. Limnol. Oceanogr. 27: 492-499

Lewis, M., Smith, J. S. (1983). A small volume, short-incubation-time method for measurement of photosynthesis as a function of incident irradiance. Mar. Ecol. Prog. Ser. 13: 99-102

Lewis, M. R., Warnock, R. E., Platt, T. (1985). Absorption and photosynthetic action spectra for natural populations: Implications for production in the open ocean. Limnol Oceanogr. 30: 794-806

Li, W. K. W., Dickie, P. M. (1985). Metabolic inhibition of sizefractionated marine plankton radiolabelled with aminoacids, glucose, bicarbonate, and phosphate in the light and dark. Microb. Ecol. 11: 11-24

Malkin, S., Kok, B. (1966). Fluorescence induction studies in isolated chloroplasts. I. Number of components involved in the reaction and quantum yields. Biochim. biophys. Acta 126: 413-432

Malkin, S., Armond, P. A., Mooney, H. A., Fork, D. C. (1981). Photosystem II photosynthetic unit sizes from fluorescence induction in leaves. Correlation to photosynthetic capacity. Pl. Physiol. 67: 570-579

Menzel, D. W., Ryther, J. H. (1960). The annual cycle of primary production in the Sargasso Sea off Bermuda. Deep Sea Res. 6: 351-367

Mitchell, B. G., Kiefer, D. A. (1984). Determination of absorption and fluorescence excitation spectra for phytoplankton. In: Holm-Hansen, O., Bolis, L., Gilles, R. (ed.) Marine 
phytoplankton and productivity. Springer-Verlag, New York, p. 157-169

Neori, A., Holm-Hansen, O., Mitchell, B. G., Kiefer, D. A. (1984). Photoadaptation in marine phytoplankton. Changes in spectral absorption and excitation of chlorophyll a fluorescence. Pl. Physiol. 76: 518-524

Neveux, J., Jupin, H. (1981). Une approche vers l'estimation de la production potentielle du phytoplancton par analyse des cinetiques d'induction de fluorescence. Mar. Biol. 63 $13-21$

Papageorgiou, G. (1975). Chlorophyll fluorescence: An intrinsic probe of photosynthesis. In: Govindjee (ed.) Bioenergetics of photosynthesis. Academic Press, New York, p. 319-371

Peterson, B. J. (1980). Aquatic primary productivity and the ${ }^{14} \mathrm{C}-\mathrm{CO}_{2}$ method: A history of the productivity problem. Ann. Rev. Ecol. Syst. 11: 359-385

Platt, T., Gallegos, C. L., Harrison, W. G. (1980). Photoinhibition of photosynthesis in natural assemblages of marine phytoplankton. J. mar. Res. 38: 687-701

Platt, T., Harrison, W. G., Irwin, B., Horne, E. P., Gallegos, C. L. (1982). Photosynthesis and photoadaptation of marine phytoplankton in the Arctic. Deep Sea Res. 29: 1159-1170

Post, A. F., Dubinsky, Z., Wyman, K., Falkowski, P. G. (1984). Kinetics of light-intensity adaptation in a marine planktonic diatom. Mar. Biol. 83: 231-238
Prézelin, B. B., Ley, A. C. (1980). Photosynthesis and chlorophyll a fluorescence rhythms of marine phytoplankton. Mar. Biol. 55: 295-307

Richardson, K., Beardall, J., Raven, J. A. (1983). Adaptation of unicellular algae to irradiance: An analysis of strategies. New Phytol. 93: 157-191

Roy, S., Legendre, L. (1979). DCMU-enhanced fluorescence as an index of photosynthetic activity in phytoplankton. Mar. Biol. 55: 93-101

Slovacek, R. E., Hannan, P. J. (1977). In vivo fluorescence determinations of phytoplankton chlorophyll a. Limnol. Oceanogr. 22: 919-925

Smith, R. E. H., Geider, R. J., Platt, T (1984). Microplankton productivity in the oligotrophic ocean. Nature, Lond. 311 : $252-254$

Vincent, W. F. (1979). Mechanisms of rapid photosynthetic adaptation in natural phytoplankton communities. I. Redistribution of excitation energy between photosystems I and II. J. Phycol. 15: 429-434

Yentsch, C. S., Yentsch, C. M. (1979). Fluorescence spectral signatures: The characterization of phytoplankton populations by use of excitation and emission spectra. J. mar. Res. 37: 471-483

This paper was submitted to the editor; it was accepted for printing on August 6,1035 